\title{
Elevadores
}

\section{A evolução da máquina elétrica}

\section{Introdução}

\section{Como seriam as nossas cidades hoje, sem elevadores?}

Os prédios teriam apenas 3 a 4 pisos e uma grande parte da arquitetura do século 19 não poderia ter sido realizada. A construção em altura como a conhecemos hoje não teria sido possível.

Para que fosse possível chegar ao nível de sofisticação das soluções de tração hoje utilizadas em elevadores, muitas diferentes fases tiveram de ser vencidas.

Nos primórdios da indústria de elevadores em finais do século 19, foram instalados os primeiros elevadores com máquinas a vapor. Assim, em 1857 foi instalado em Nova lorque, num edifício na esquina da Broadway e Broome Street, o primeiro elevador de pessoas, com um sistema de tração a vapor.

Com o surgimento da eletrificação das cidades e dos motores eléctricos, as máquinas a vapor rapidamente caíram em desuso como sistema de tração para elevadores.

Apesar de hoje ainda serem utilizados outros sistemas de tração, como por exemplo sistemas hidráulicos, no presente artigo iremos abordar apenas a evolução da máquina elétrica nos elevadores.

\section{Uma breve perspetiva histórica}

Até 1878 , os principais ascensores de pessoas instalados eram movidos por poderosas máquinas a vapor, permitindo que se pudesse aceder aos pisos mais altos de um edifício de uma forma confortável. Nesse ano foi instalado o primeiro elevador hidráulico de pessoas no edifício Broadway 155 em Nova lorque.

Em 1889 foi produzido nos Estados Unidos o primeiro elevador elétrico com uma máquina constituída por um motor elétrico acoplado a um redutor por roda de coroa e parafuso sem fim. Obtinha-se desta forma a velocidade linear requerida para a cabina do elevador. Esta solução foi inicialmente instalada apenas em elevadores de carga.

Apesar de o ascensor elétrico ser mais compacto, o elevador com máquina a vapor permitia que se atingissem velocidades superiores, o que era muito importante para os edifícios cada vez mais altos que se estavam a construir na época.

Com o desenvolvimento de novos redutores foi possível ao longo dos anos aumentar a velocidade nominal do elevador de $0,5 \mathrm{~m} / \mathrm{s}$ para $2,0 \mathrm{~m} / \mathrm{s}$, permitindo que o ascensor elétrico passasse a ser interessante também para o transporte de pessoas em edifícios de maior altura.

Em 1891, com o surgimento do sistema Ward-Leonard desenvolvido pelo engenheiro electrotécnico americano Harry Ward Leonard, foi possível desenvolver sistemas de elevadores com máquinas elétricas de alta velocidade e de velocidade variável.

Com o surgimento dos variadores eletrónicos de frequência a partir da década de 80 do século 20, foi possível implementar sistemas de tração elétricos para elevadores que garantiam velocidades elevadas, com um maior conforto de andamento e com um muito inferior consumo de energia elétrica.

Actualmente com as máquinas com motores síncronos de ímans permanentes e sem redutor, controladas por modernos variadores eletrónicos de frequência, é possível não só otimizar o espaço necessário para a instalação do elevador (a não necessidade de casa de máquinas, por exemplo), mas também atingir a classe de eficiência energética mais elevada (Classe A), de acordo com a VDI4707 ${ }^{1}$ 
3. As caraterísticas técnicas relevantes numa máquina elétrica de elevador

Apresentam-se na tabela 1 as máquinas elétricas que mais foram / ainda são utilizadas em elevadores, indicando o tipo de motor e o respetivo método de controlo da velocidade.

\section{Máquina com redutor e motor assíncrono de uma velocidade}

Os ascensores correntes instalados em edifícios não muito altos eram equipados com máquinas constituídas por motores assíncronos de indução de uma só velocidade. O motor de indução permitia uma velocidade constante, sendo alimentado por uma fonte de energia elétrica de tensão e frequência constantes. A sua velocidade de funcionamento em regime nominal era muito próxima da velocidade síncrona $^{2}$. Quando o binário da carga aumentava, a velocidade do motor decrescia apenas ligeiramente.

Estes motores arrancavam frequentemente ligados diretamente à fonte de alimentação, absorvendo uma elevada corrente de arranque, tipicamente 4 a 6 vezes da corrente absorvida quando o motor funciona em plena carga.
Por forma a reduzir a intensidade no período de arranque, foi adoptado ainda o método de arranque estrela-triângulo. A ligação em funcionamento normal da bobinagem do motor era em triângulo. $\mathrm{Na}$ fase do arranque, contudo, a bobinagem era colocada em estrela, havendo lugar a uma menor corrente absorvida. Quando o motor se aproximava da velocidade nominal, a bobinagem era novamente colocada em triângulo.

Para parar a cabina do ascensor, o contactor desligava a alimentação elétrica e o travão da máquina era imediatamente activado ainda com a máquina em movimento à velocidade nominal (tipicamente $0,6 \mathrm{~m} / \mathrm{s}$ ), o que provocava um elevado desgaste nas cintas do travão.

Com a variação da carga na cabina, a temperatura e o estado do travão, por vezes não se conseguia garantir uma paragem nivelada com o piso (surgia um "ligeiro" degrau, que era muitas vezes fonte de queda de pessoas).

Estas máquinas tinham como grandes vantagens uma elevada robustez com reduzida manutenção.

Tabela 1 - Tipos de máquinas elétricas utilizadas em elevadores

\begin{tabular}{|l|l|l|}
\hline Tipo de Máquina & Tipo de Motor & Controlo \\
\hline Com Redutor & Assincrono de uma velocidade & Por contactor, diretamente \\
\hline & Assincrono de duas veleocidades & Por contactores, diretamente \\
\hline Assincrono de uma velocidade & Por variação de frequência \\
\hline De corrente contínua & Por sistema Ward-Leonard \\
\hline & Síncrono de ímans permanentes & Por variador de frequência \\
\hline
\end{tabular}

1 A norma alemã VDI 4707:2009 foi publicada em Março de 2009 pela Associação dos Engenheiros Alemães (Verein Deutscher Ingenieure). É assim possível realizar uma avaliação e classificação universal e transparente da eficiência energética de ascensores, com base em critérios standardizados.

2 Para este tipo de motores a velocidade do motor em regime permanente é inferior à velocidade síncrona. 
Na figura 1 apresenta-se um exemplo de uma máquina com redutor e motor assíncrono de uma velocidade Schmitt+Sohn.

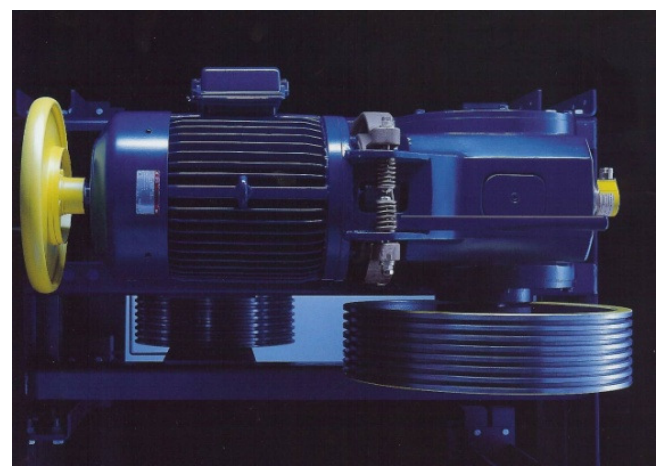

Figura 1 - Máquina assíncrona de um velocidade (Fonte: Schmitt+Sohn Elevadores)

Máquinas com redutor e motor assíncrono de duas velocidades

Por forma a reduzir as sacudidelas bruscas no arranque e principalmente na paragem da máquina, mantendo ainda assim uma elevada velocidade nominal, e sem grande necessidade de um sistema de controlo da velocidade complexo, foram introduzidos motores assíncronos de dois enrolamentos com um número de par de pólos diferente.

Um enrolamento para a grande velocidade (com menor número de pares de pólos) e um enrolamento para a pequena velocidade (com maior número de pares de pólos). Esta última representa normalmente $1 / 4$ ou $1 / 6$ da velocidade nominal.

Desta forma conseguia-se garantir uma elevada velocidade nominal, por um lado, e uma reduzida velocidade de paragem, por outro, obtendo-se uma paragem mais suave e mais nivelada ao piso. Através de dois contactores eram acionados sequencialmente os dois enrolamentos. A sacudidela brusca que ocorria na comutação (arranque e paragem) era atenuada por um volante de inércia.
Para garantir que o elevado número de rotações e o baixo binário caraterísticos deste tipo de motor assíncrono pudessem ter aplicação em ascensores, foram adaptados redutores de sem fim com roda de coroa. Com estas máquinas conseguiam-se velocidades nominais até $1,2 \mathrm{~m} / \mathrm{s}$. A travagem era efetuada por duas maxilas cuja abertura e fecho se realizava por bobinas elétricas. A actuação decorre com a máquinas ainda em movimento por inércia, na segunda velocidade (baixa velocidade).

Este tipo de motor era o mais frequentemente utilizado até ao surgimento da máquina controlada por variador de frequência, estando ainda hoje em funcionamento em muitos prédios em Portugal.

Tratava-se de uma máquina de fácil conceção, muito robusta e de baixo custo de produção, não sendo hoje já instalada em novos elevadores.

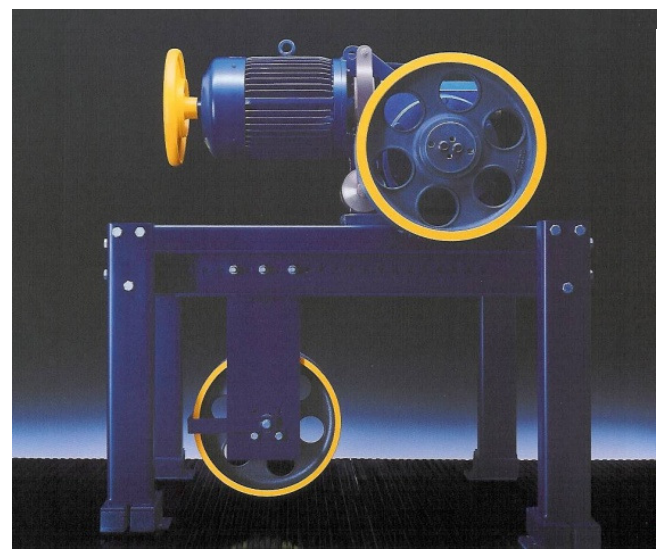

Figura 2 - Máquina assíncrona de duas velocidade (Fonte: Schmitt+Sohn Elevadores)

\section{Máquinas de corrente contínua}

Os motores de corrente contínua eram utilizados quando se pretendia uma velocidade superior e o controlo através dos dois enrolamentos não era suficiente.

Adotava-se então o sistema Ward-Leonard (ver figura 3). 
O sistema de tracção Ward-Leonard era composto por um conversor motor/gerador que transformava a corrente alternada em corrente contínua e por um grupo motor de corrente contínua com redutor (a máquina de tração do elevador), interligado eletricamente.

Por sua vez, o conversor era constituído por um motor assíncrono alimentado diretamente a partir da rede elétrica, que estava acoplado mecanicamente a um gerador de corrente contínua que produzia uma tensão contínua, que alimentava o motor.

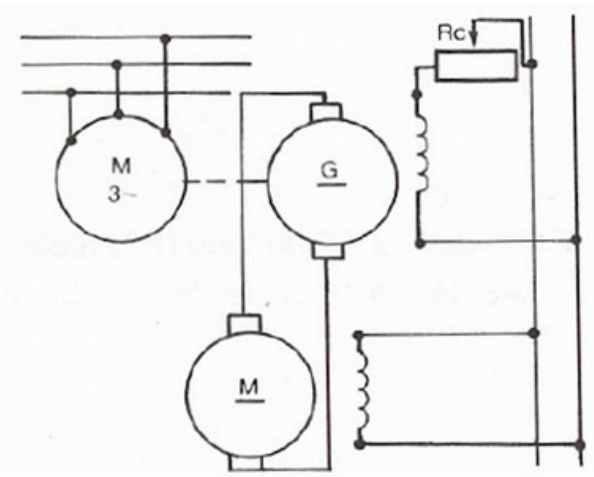

Figura 3 - Esquema do sistema Ward-Leonard

A variação de velocidade da máquina com motor de corrente contínua e redutor (a máquina de tração do elevador), faziase através da corrente contínua produzida pelo gerador e controlada automaticamente através do quadro de comando e gestão, em paralelo com um taquímetro colocado no veio do motor. Desta forma regulava-se a injeção de mais ou menos corrente no motor e no seu circuito de excitação, de forma a variar a sua velocidade para mais ou menos, consoante as necessidades operacionais das solicitações.

O sistema Ward-Leonard possibilitou a existência de sistemas de tração com velocidade variável. O binário de carga podia ser aumentado sem que tal se refletisse numa sobrecarga da rede de alimentação.

Este sistema, além de ruidoso, era o único que permitia o controlo de máquinas potentes com variação de velocidade, até ao surgimento do variador eletrónico de frequência.
O sistema Ward-Leonard implicava a utilização de mais espaço na casa das máquinas, e era uma solução bastante mais onerosa, quer na aquisição, quer na sua manutenção e na sua operação (envolvia vários motores e um maior consumo energético, devido entre outros ao baixo rendimento de todo o sistema), pelo que já não é utilizado atualmente.

\section{Máquinas com motores assíncronos controladas por variador de frequência}

Com a evolução da tecnologia e com a resultante entrada em vigor de novas normas e regulamentos, nomeadamente do Decreto-Lei 163/2006 de 8 de Agosto (que define as condições de acessibilidade a edifícios por parte de pessoas com mobilidade reduzida), os ascensores devem ter uma precisão de paragem relativamente ao nível do piso dos patamares não superior a $\pm 0,02 \mathrm{~m}$. Ora tal obrigatoriedade não pode ser cumprida recorrendo a máquinas com redutor e motor de duas velocidades. Por forma a dar cumprimento às novas exigências foi necessário utilizar outros tipos de máquinas: uma das soluções possíveis encontrada, foi a máquina com motor assíncrono, mas controlado por variador eletrónico de frequência.

A velocidade do motor pode ser variada pela alteração da frequência da alimentação do mesmo. Da equação (1) seguinte é possível perceber a relação entre a velocidade de rotação do rótor da máquina e a frequência da fonte de alimentação:

$$
s=\frac{n_{s}-n_{r}}{n_{s}} \rightarrow n_{r}=(1-s) \frac{f}{p}
$$

Com:

$f$ - frequência de alimentação

p-número de pares de pólos

$\mathrm{nr}$ - velocidade angular de rotação do rótor

ns - velocidade de síncrona do campo girante

$\mathrm{s}$ - deslizamento (diferença entre a velocidade síncrona do campo girante e a velocidade do rótor) 
A aplicação deste método de controlo de velocidade requer por isso um variador eletrónico de frequência.

Os variadores de frequência convertem a tensão alternada da rede de $50 \mathrm{~Hz}$ numa tensão contínua e em seguida numa tensão com frequência variável, conforme indicado na figura 4.

$\mathrm{Na}$ sua aplicação em ascensores a frequência variará tipicamente entre 0 e $50 \mathrm{~Hz}$. Durante a fase de paragem do ascensor, é o próprio variador de frequência que leva a máquina até uma velocidade zero, sendo a frequência de alimentação gradualmente reduzida.

Neste processo, a velocidade instantânea do sistema é superior à velocidade síncrona, devido à inércia do sistema.

A ação geradora do motor irá causar uma inversão no sentido do fluxo da potência, e a energia cinética do sistema é dissipada pela resistência. Só quando a máquina estiver completamente parada é que é atuado o sistema de travão.
Na figura 5 apresenta-se um moderno variador eletrónico de frequência, normalmente instalado no próprio quadro de comando do elevador.

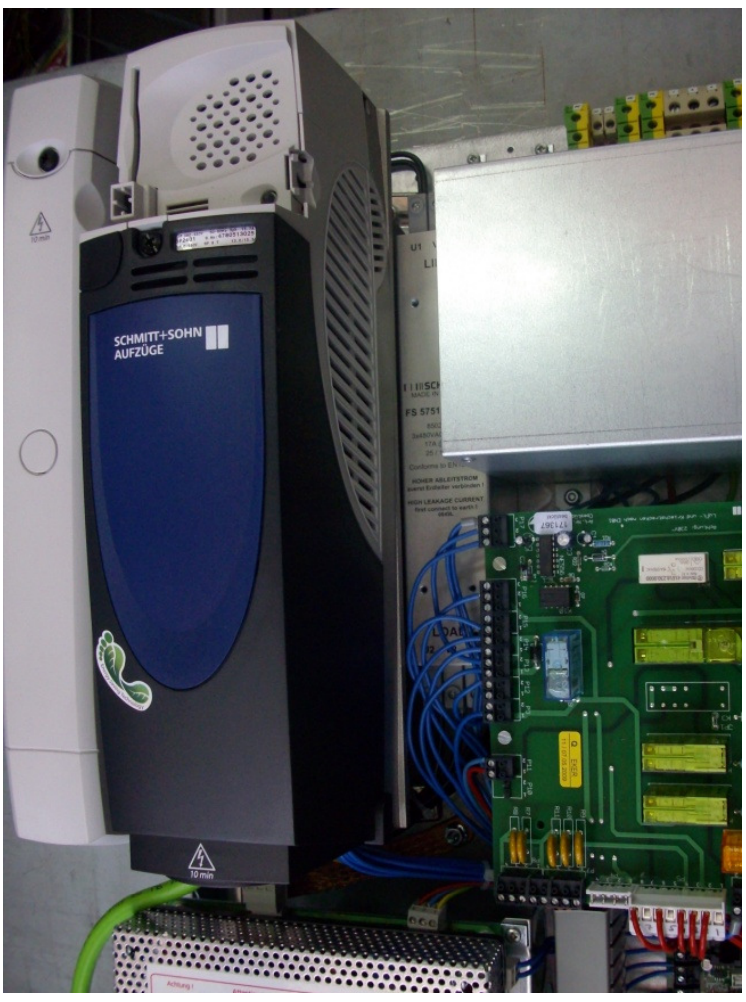

Figura 5 - Variador eletrónico de frequência

(Fonte: Schmitt+Sohn Elevadores)

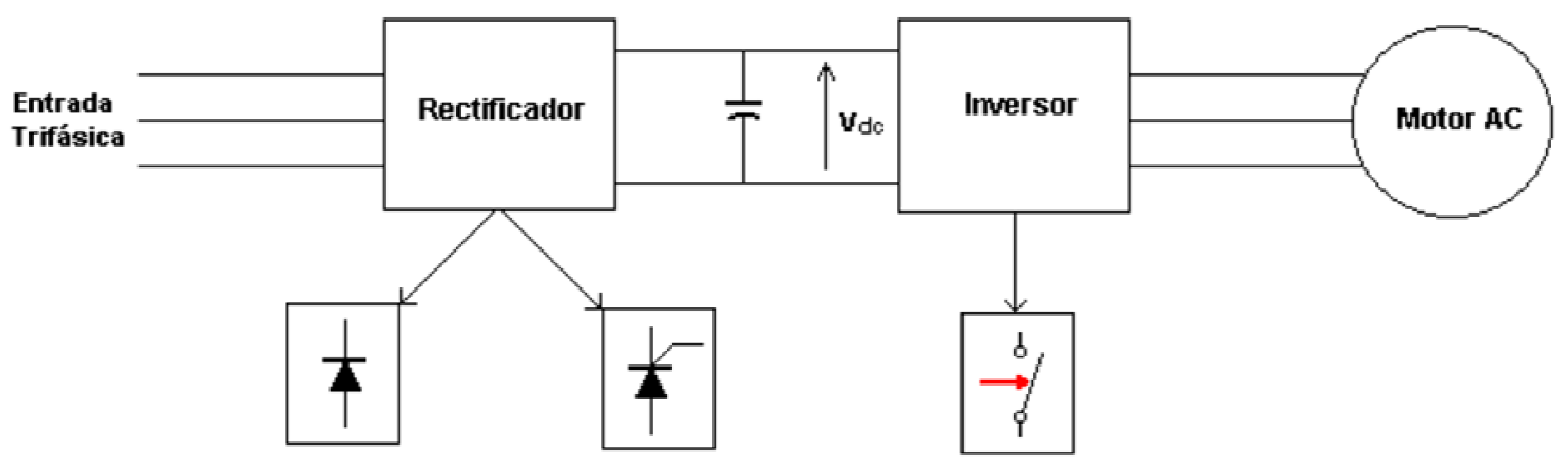

(I) (II)

Figura 4 - Esquema de funcionamento de um variador eletrónico de frequência (Fonte: Pedro Sousa Melo - ISEP 2006) 
As principais vantagens resultantes da utilização de variadores eletrónicos de frequência são:

1. Elevado rendimento e elevada fiabilidade

2. Elevado fator de potência

3. Adaptação do motor à carga, em binário e velocidade

4. Arranques suaves e frenagem controlada

5. Proteção do motor contra curtos-circuitos, sobrecargas, sobretensões, falta de fase

6. Menor desgaste de componentes e equipamentos mecânicos

\section{Máquinas de motores síncronos com ímans permanentes} controlados por variadores de frequência

O estado da arte é representado pelas máquinas com motores síncronos com ímans permanentes controlados por variadores eletrónicos de frequência.

Estas máquinas conseguem um elevado binário com baixas rotações, evitando-se dessa forma a necessidade de um redutor. Obtém-se um funcionamento com baixo ruído, com baixo custo de operação e manutenção e um elevado rendimento. Por outro lado, a sua reduzida dimensão, permite que se maximize o espaço útil para a instalação da cabina nos modernos elevadores sem casa das máquinas.

No rótor são instalados potentes ímans permanentes e no estator são montados até 32 pares de pólos. A frequência máxima fica assim bastante abaixo dos $50 \mathrm{~Hz}$, pelo que será necessário recorrer a um variador de frequência para controlar a máquina.

Estas máquinas têm um rendimento muito superior, permitindo uma significativa poupança energética.

Durante a fase de paragem do ascensor, é o próprio variador de frequência que leva a máquina até uma velocidade zero. Só então é atuado o sistema de travão. Estas máquinas são dotadas de um sistema especial de travões de disco.

Com estas máquinas conseguem-se obter altas velocidades na ordem dos 3 a $4 \mathrm{~m} / \mathrm{s}$, com baixos consumos energéticos.

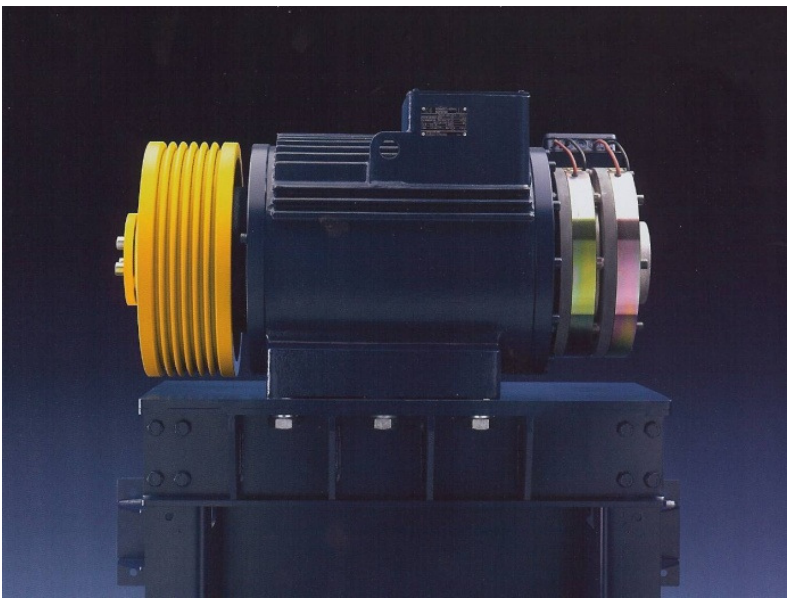

Figura 7 - Máquina com motor síncrono com ímans permanentes sem redutor

(Fonte: Schmitt+Sohn Elevadores)

Com a aplicação de um variador eletrónico de frequência de última geração, é possível com estas máquinas elétricas proceder à recuperação de energia, que poderá ser injectada na rede eléctrica do edifício ou no barramento de corrente contínua em que estão interligados os (eventuais) diferentes variadores de frequência de uma bateria de ascensores. Desta forma o rendimento global do sistema pode ser significativamente melhorado.

\section{Conclusão}

Foram apresentadas resumidamente as principais máquinas elétricas utilizadas em elevadores, desde a máquina com redutor e com motor assíncrono de uma só velocidade, passando pela máquina com redutor e com motor assíncrono de duas velocidades até à máquina com motor de corrente contínua controlado por variação de tensão (estas três soluções já não são aplicadas em novos elevadores).

Seguidamente analisou-se a máquina com redutor e motor assíncrono mas controlado por variador eletrónico de frequência, para finalmente se apresentar a máquina sem redutor com motor de ímans permanentes, controlada por variador eletrónico de frequência, o actual estado da arte. 
Na tabela 2 apresenta-se uma comparação da potência, das correntes de arranque e nominal das diferentes máquinas estudadas (com exceção da máquina com o motor de corrente contínua) para um elevador com uma carga nominal de $630 \mathrm{~kg}$ e uma velocidade nominal de $1,0 \mathrm{~m} / \mathrm{s}$.

Verifica-se que a máquina sem redutor com motor síncrono de ímans permanentes e com variador eletrónico de frequência é a solução que apresenta a potência mais reduzida $(2,9 \mathrm{~kW})$ face aos $7,5 \mathrm{~kW}$ necessários para uma máquina com redutor e com motor assíncrono de uma só velocidade. Se para esta última a corrente de arranque é de $50 \mathrm{~A}$, ou seja 3,3 vezes a corrente nominal, na máquina sem redutor com motor síncrono de ímans permanentes a corrente de arranque representa apenas $21 \mathrm{~A}$, ou seja 1,6 vezes a corrente nominal.

\section{Bibliografia}

[1] BARNEY, Gina - Elevator Traffic Handbook - Theory and Practice. Nova lorque, Spon Press, 2003. ISBN 0-41527476-I.
[2] BELEZA CARVALHO, José - Máquinas Assíncronas de Indução. Porto, ISEP, 2008.

[3] FITZGERALD, A.; KINGSLEY, Charles; UMANS, Stephen Electric Machinery. Nova lorque, McGraw Hill, 2003. ISBN 0-07-123010-6.

[4] FRANCHI, C. - Acionamentos Eléctricos. Editora Érica, Ltda, 2007. ISBN 978-85-365-0149-9.

[5] MATIAS, José - Máquinas Eléctricas. 5a Edição. Lisboa, Didáctica Editora, 2005. ISBN 972-650-124-5.

[6] MELO, Pedro - Motor de Indução Trifásico. Porto, ISEP, 2006.

[7] PALMA, João - Accionamentos Electromecânicos de Velocidade Variável. 2a Edição. Lisboa, Fundação Calouste Gulbenkian - Serviço de Educação e Bolsas, 2008. ISBN 978-972-31-0839-2.

\section{Directivas, Leis e Normas}

[1] DECRETO-LEI 163/2006 de 08 de Agosto. Diário da República, 1a Série - № 152, página 5670 ss.

[2] NORMA ALEMÃ VDI 4707:2009 - Ascensores - Eficiência Energética (2009), Verein Deutscher Ingenieure (VDI).

\begin{tabular}{|c|c|c|c|c|}
\hline Tipo de Máquina & $\begin{array}{l}\text { Máquina com } \\
\text { redutor e com } \\
\text { motor } \\
\text { assíncrono de } \\
\text { uma velocidade }\end{array}$ & $\begin{array}{l}\text { Máquina com } \\
\text { redutor e com } \\
\text { motor } \\
\text { assíncrono de } \\
\text { duas velocidade }\end{array}$ & $\begin{array}{l}\text { Máquina com } \\
\text { redutor e com } \\
\text { motor assíncrono } \\
\text { com variação de } \\
\text { frequência }\end{array}$ & $\begin{array}{l}\text { Máquina sem redutor } \\
\text { com motor síncrono } \\
\text { com ímans } \\
\text { permanentes e com } \\
\text { variação de frequência }\end{array}$ \\
\hline Carga nominal da máquina & 630 & 630 & 630 & 630 \\
\hline $\begin{array}{l}\text { Velocidade nominal da } \\
\text { cabina }(\mathrm{m} / \mathrm{s})\end{array}$ & 1,0 & 1,0 & 1,0 & 1,0 \\
\hline Tipo de suspensão & $1: 1$ & $1: 1$ & $1: 1$ & $2: 1$ \\
\hline $\begin{array}{l}\text { Potência } \\
\text { (kW) }\end{array}$ & 7,5 & 6 & 5,5 & 2,9 \\
\hline $\begin{array}{l}\text { Intensidade de arranque } \\
\text { (A) }\end{array}$ & 50 & 49 & 30 & 21 \\
\hline $\begin{array}{l}\text { Intensidade nominal } \\
\text { (A) }\end{array}$ & 15 & 13 & 12 & 13 \\
\hline
\end{tabular}

Tabela 2 - Comparação das potências e correntes de arranque e nominal das diferentes máquinas eléctricas utilizadas em elevadores (Fonte: Schmitt+Sohn Elevadores) 